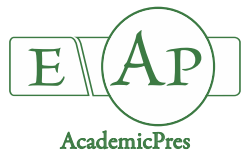

\title{
Cross Compatibility Analysis to Identify Suitable Parents of Tagetes erecta and $T$. patula for Heterotic Hybrid Breeding
}

\author{
Huali ZHANG ${ }^{1}$, Haibo XIN ${ }^{1}$, Richen $\mathrm{CONG}^{1}$, Zijing $\mathrm{LI}^{1}$, Lina SONG ${ }^{1}$, \\ Zunzheng WEI ${ }^{2 *}$ \\ ${ }^{1}$ Beijing Institute of Landscape and Architecture, Beijing Key Lab of Green Plant Breeding, No.7 Huajiadi, Chaoyang District, Beijing, \\ China; lilytalk2002@163.com;zghbzpx@163.com; hardhopeee@163.com;lizijing8314@126.com;songln_009@126.com \\ ${ }^{2}$ Beijing Vegetable Research Center, Beijing Academy of Agriculture and Forestry Sciences, Key Laboratory of Biology and Genetic Improvement of \\ Horticultural Crops (North China), Key Laboratory of Urban Agriculture (North China), Ministry of Agriculture and Rural Affairs, Beijing \\ Engineering Technology Research Center of Functional Floriculture, Zhanghua Road No. 50, Haidian District, Beijing, \\ China;weizunzheng@163.com (*corresponding author)
}

\begin{abstract}
Seven interspecific crosses of Tagetes erecta $\times T$. patula were conducted in this study. The cross compatibility index, seed setting rate, germination rate, phenotype, ploidy level, heterosis over male parent and field performance were tested. The results showed that different cross compatibility indices of Tagetes vary greatly, from 10.44 114.41, which is far less than that of the intraspecific hybridization S-121 × I-506 index. The seed setting rate of each cross ranged from $15.67 \%$ to $49.0 \%$, and the cross S-121 $\times$ TP-512 scored the highest seed setting rate, which was higher than that of the intraspecific cross S-121 $\times$ I506 (35.85\%). Compared with the male parent, $F_{1}$ has higher plant height, wider crown width, larger flower diameter and more ray florets and earlier bloom with two exceptions. The S-121 of T. erecta was diploid. All of the male parents of T. patula were tetraploids, and the combinations were triploids. The traits of plant height, plant width, flower size and number of ray florets showed positive heterosis over the male parents, and the days leading to flowering showed both positive and negative ones. Finally, S-121 × TP-379 and S-121 × TP-512 were selected as the two best combinations. This study confirmed that the two species of marigold could be crossed for better $F_{1}$ varieties with improved performance.
\end{abstract}

Keywords: heterosis; interspecific hybridization; Tagetes erecta; T. patula

\section{Introduction}

Both Tagetes erecta and T. patula are annual flowers in the Asteraceae family and are native to South America and Mexico (He et al., 2016). They can be grown under a broad range of climatic conditions and thus are cultivated worldwide. Tagetes erecta, often called the African marigold, has fully double flowers in various brilliant colors of variable height. It is of great importance for landscaping and can be used as bedding and as a potted plant which make a magnificent garden from spring to autumn. Tagetes patula, often called the French marigold, belongs to the genus Tagetes spp. The specie is one of the most important annual ornamental plants in commercial cultivation ( $\mathrm{Ai}$ et al., 2015; Cicevan et al., 2016). The French marigold is different from the African marigold in many ornamental traits. The former is smaller in flower size, dwarf and compact in the whole plant, and it has more flowers on each individual plant.
The common method of commercial seed production for marigolds is crosses by using male sterile lines as female parents for cross breeding purposes (Sreekala and Raghava, 2003; Namita et al., 2011; Ai et al., 2017). To date, an intraspecific cross has been developed to produce new varieties and seeds in $T$. erecta (Zhang et al., 2014). In this system, using male sterile lines of $T$. erecta as parents avoided the large manual work of emasculation to obtain $F_{1}$ hybrid seeds at a commercial production scale (He et al., 2009). Varieties of $T$. patula are inbreeding varieties and could be crossed with $T$. erecta as male parents (Li et al., 2005; Namita et al., 2009; Namita et al., 2011). F hybrids of $T$. erecta $\times$ T. patula are often called triploid marigold and have a longer flowering duration (Namita et al., 2011). Few varieties of triploid marigold could be found in seed companies. One of the series was 'Zenith', including several colors. In ornamental plant breeding, interspecific hybridization is often used in combination as a system to 
achieve cross breeding goals. For marigolds, Li et al. (2005) carried out the research about interspecific crosses between $T$. erecta and $T$. patula and selected two sterile combinations. Namita et al. (2011) used three male sterile lines of $T$. erecta and eleven inbred lines of $T$. patula and tested the general combination ability and specific combining ability of their 33 hybrids. He et al. (2016) conducted interspecific crosses between the mutated tetraploid male sterile $T$. erecta plants and fertile tetraploid $T$. patula lines. Ai et al. (2014) first reported a novel pollen abortion mutant of $T$. patula by heat shock. Heterosis can be fully utilized by distant hybridization in ornamentals $(\mathrm{Li}$ et al., 2005; Baciu et al., 2012). This research had enriched the germplasm resources and breeding theory and practice for the interspecific hybridization of marigold. However, to date, there is still little data about the distant breeding concern $T$. erecta $\times T$. patula, and few varieties of triploid marigold appear in the seed market.
Maintaining the concept of the importance and limited related research about marigolds, the objectives of this research were to: (1) create new crosses between two marigolds species to create new varieties with dwarf, compact, early flowering, double flower and vigorous growth traits, and (2) elucidate the heterosis over the male parents, and elucidate the difference between $T$. patula and $T$. erecta $\times T$. patula.

\section{Materials and Methods}

\section{Plantmaterials}

One male sterile line of $T$. erecta (S-121) was designated as the female parent, while seven accessions of $T$. patula (TP-508, TP-509, TP-510, TP-511, TP-512, TP-515 and TP-379) and one $T$. erecta inbred line (I-506) were used as the male parents. The main traits of the parental lines are described in Table 1 and Fig. 1.

Table 1. The main characteristics and origin of the parental lines of T. erecta and T.patula

\begin{tabular}{|c|c|c|c|c|c|c|}
\hline Species & Accession & Flower color & Flower type & Line & Ploidy level & Source \\
\hline \multirow[t]{2}{*}{ T. erecta } & $S-121$ & Yellow & $\begin{array}{c}\text { Double }(\delta) \\
\text { Apetalous }(q)\end{array}$ & Male sterile & $2 x$ & \multirow{2}{*}{$\begin{array}{c}\text { Beijing Institute of } \\
\text { Landscape Architecture }\end{array}$} \\
\hline & I-506 & Orange & Single & Inbred lines & $2 x$ & \\
\hline \multirow{7}{*}{ T.patula } & TP-508 & Yellow & Anemone & Inbred variety & $4 x$ & \multirow{5}{*}{$\begin{array}{c}\text { PanAmerican Seed } \\
\text { Company }\end{array}$} \\
\hline & ТР-509 & Orange & Anemone & Inbred variety & $4 x$ & \\
\hline & ТР-510 & Yellow & Crested & Inbred variety & $4 x$ & \\
\hline & ТР-511 & Orange & Crested & Inbred variety & $4 x$ & \\
\hline & ТР-512 & Red & Anemone & Inbred variety & $4 x$ & \\
\hline & TP-515 & Orange & Double & Inbred variety & $4 x$ & \multirow{2}{*}{$\begin{array}{c}\text { American Seed } \\
\text { Company }\end{array}$} \\
\hline & ТР-379 & Yellow & Anemone & Inbred variety & $4 x$ & \\
\hline
\end{tabular}
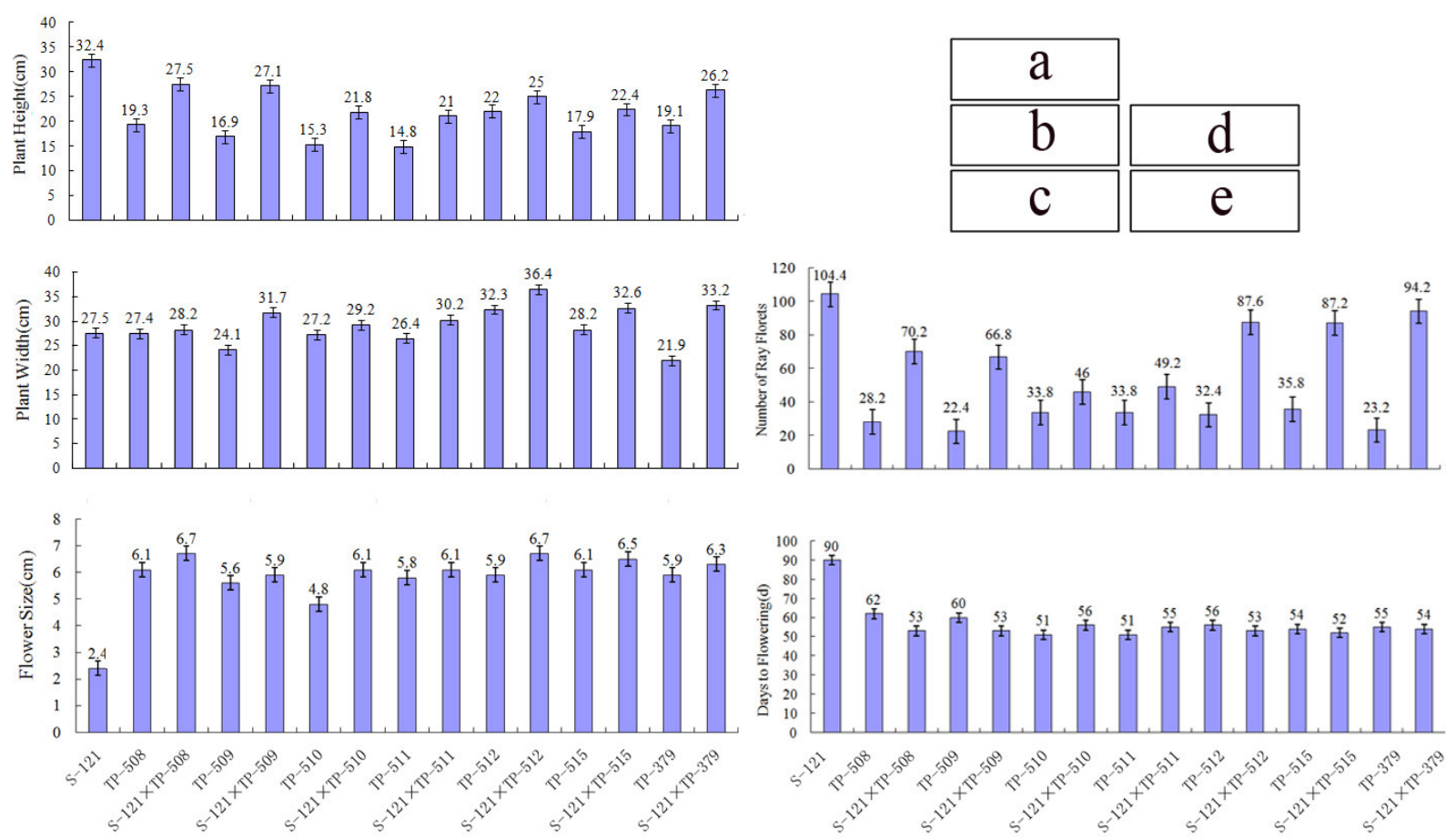

Fig.1. The phenotypic trait comparison of T. erecta, T. patula and their $\mathrm{F}_{1}$ hybrids 
678

\section{Artificial pollination}

The study was conducted at the Beijing Institute of Landscape and Architecture, Beijing, China. The artificial pollination was conducted at the greenhouse in the autumn of 2015, and the field trial was conducted at the open experimental field in the spring of 2016. To ensure that the flowers of S-121 and the male parents engaged, the male sterile line of S-121 was sown in July $2^{\text {nd }}(2015)$, and the rest of the materials were sown 18 days later. A total of 200-hole plugs were used for seed germination and the seedlings were transplanted into 12-hole plugs after another 4 week. The medium was the mixture of peat and vermiculite $4: 1$ which contains approximately $2 \mathrm{~g}$ of $14-13-13$ as base fertilizer per pot. Water soluble fertilizer, such as 14-0-14 and 20-10-20, was applied at approximately $50 \sim 100 \mathrm{mg} / \mathrm{L}$ and watered and fertilized alternately. When the flower buds emerged, the water soluble fertilizer was applied at 10-30-20 every 15 days with the concentration approximately $200 \mathrm{mg} / \mathrm{L}$.

The seven male lines were pinched for better branching and additional flowers. These plants bloomed approximately 60 days after transplantation. All of the crosses were created using artificial pollination. The crosses were carried out from September 28th to October 26th (2015) when their flowers were fully opened. Thirty male sterile plants and 144 plants of $T$. patula were used in this study in total. All of the pollen of each cross was collected on the same day, and pollination was started at the same time. For each cross, the pollen of the corresponding parent was collected on a sunny day morning after 10:00 AM. The flowers were bounced by hand, and the pollen dropped into a glass culture dish. The pollen was used to pollinate the male sterile plants of $S-121$ by a brush every other day and repeated 3 4 times to maintain enough pollen. More than 20 flowers were pollinated in each cross. The seeds were harvested and separately detailed in the gauze bags approximately 20 days later and stored at $4{ }^{\circ} \mathrm{C}$.

\section{Field trial, data collection and statistical analysis}

The field trials were conducted between February $16^{\text {th }}$ and July $4^{\text {th }}, 2016$. The plants of the $F_{1}$ and parental lines were sown in February $16^{\text {th }}$ and cultured under the same conditions as artificial pollination. The seven $F_{1}$ combinations and parents were evaluated in a randomized complete block design with three replicates, and each replicate contained 24 plants. The plants were transplanted into the open field on April 25 $5^{\text {th }}$ (2016) with an inter-row spacing of $40 \mathrm{~cm}$ and grown under natural conditions. All the selected genotypes were treated uniformly with cultural practices for healthy growth and development.

Measurements of the ornamental traits were carried out from May $10^{\text {th }}$ to June $20^{\text {th }}$, the time that all the plants were in full bloom. Five plants were randomly selected for each replicate. Ornamental traits, including plant height, width, flower color, flower size, flower type, number of ray florets and days leading to flowering were recorded. The mean and heterosis over male-parent (MP) values were calculated using the formula $100 \times\left(\mathrm{F}_{1}-\mathrm{MP}\right) / \mathrm{MP}$. For different crosses, four to 33 capitulums were selected to calculate the distant hybridization cross compatibility index and seed setting rate. The distant hybridization cross compatibility index was calculated using the formula: seed number / capitulum number. Full seed number refers to the number of seeds which contain testa and embryo and developed from ovules. The seed setting rate was counted by the formula full seed number / flower number of one capitulum $\times 100 \%$. The germination rate was counted using the formula germination number / total seed number $\times 100 \%$. The cross compatibility, the seed number, seed setting rate, germination and heterosis were calculated using SPSS Statistics 17.0. In addition, the LSD (least significant difference) was used for multiple comparisons to determine the significant differences $(P<0.05)$ among the combinations for the mean values for each characteristic.

\section{Chromosome counting and Flow cytometry analysis}

The chromosomes were counted as previously described by Zhu (1982).

Accuri C6 flow cytometry (BD Company, the United States) was used to conduct a flow cytometry analysis. The tender leaves (approx. $50 \mathrm{mg}$ ) were added to the precooled plate to which the precooled $1 \mathrm{~mL}$ lysate was added (LB01, Wu et al., 2016), and the leaves were quickly chopped with a sharp blade. In the process, the leaves should be soaked in the lysate. The supernatant of the prepared cell suspension was discarded. One hundred microliters of precooled lysis solution was added to $150 \mu \mathrm{L}$ propidium iodide (PI) working solution and dye and placed at $4{ }^{\circ} \mathrm{C}$ for $10 \mathrm{~min}$ out of the light. Each sample was tested with 3 repeats, with at least 10000 cells with FL2-A channel meter. The CV (coefficient of variation) was less than 5\%. The data was collected using CFlow Plus software (Wu et al., 2016).

\section{Results and Discussion} patula

Analysis of the cross compatibility index of T. erecta $\times T$.

The cross compatibility index of the two Tagetes is shown in Table 2. The index of the seven crosses vary greatly, from 10.44 121.67; in particular, S-121 × TP-510 and S-121 $\times$ TP-511 display lower values of 19.93 and 10.44 , respectively. In addition, the cross $S-121 \times \mathrm{TP}-512$ had the highest value among the interspecific crosses. The intraspecific hybridization S-121 $\times$ I-506 showed the highest cross compatibility index of 121.67 .

When the value of the compatibility index is zero, it is proven that the parent cannot produce $\mathrm{F}_{1}$ seed. Li et al. (2008) reported that the highest compatibility index was low with a mean value of 5.4 when the crosses were made using the diploid species of Dendranthema lavandulifoium, $D$. dichrum and $D$. nankingense. This study shows a high cross compatibility index and indicates that the crosses between the two species are compatible and there is no prefertilization barrier.

\section{Analysis of seed setting rate and germination rate}

The full seed numbers, total seed numbers per capitulum and seed setting rate of each cross are listed in Table 3. The number of full seeds varies greatly, from 36 to 122. S-121 $\times$ I-506 had the maximum number of full seeds with 122 and it has a significant difference with the crosses of S-121 × TP-508, S-121 × TP-510 and S-121 × TP-511. There is no significant difference in the total seed number 
Table 2. The cross compatibility index of $T$. erecta $\times$ T. patula

\begin{tabular}{|c|c|c|c|}
\hline Cross & Seed number & Capitulum number & Cross compatibility index \\
\hline S-121 × TP-379 & 1763 & 19 & 92.79 \\
\hline S-121 $\times$ TP- 508 & 397 & 6 & 66.17 \\
\hline S-121 × ТP-509 & 1674 & 16 & 104.63 \\
\hline S-121 $\times$ TP- 510 & 279 & 14 & 19.93 \\
\hline S-121 $\times$ TP-511 & 94 & 9 & 10.44 \\
\hline S-121 $\times$ TP- 512 & 1945 & 17 & 114.41 \\
\hline S-121 $\times$ TP- 515 & 359 & 4 & 89.75 \\
\hline S-121 × I-506 & 4015 & 33 & 121.67 \\
\hline
\end{tabular}

Table 3. Seed setting rate and germination rate in different crosses of T. erecta $\times$ T.patula

\begin{tabular}{|c|c|c|c|c|c|c|}
\hline \multirow{2}{*}{ Cross } & \multicolumn{2}{|c|}{ Full seeds number } & \multicolumn{2}{|c|}{ Total seed number per capitulum } & \multirow{2}{*}{$\begin{array}{c}\text { Seed setting rate } \\
(\%)\end{array}$} & \multirow{2}{*}{$\begin{array}{c}\text { Germination rate } \\
(\%)\end{array}$} \\
\hline & Average & Extreme & Average & Extreme & & \\
\hline S-121 × TP-379 & $93 \mathrm{ac}$ & $45 \sim 136$ & $250 \mathrm{a}$ & $217 \sim 294$ & 37.83 abe & 84.0 af \\
\hline S-121 × TP-508 & $66 \mathrm{bcd}$ & $14 \sim 132$ & $213 \mathrm{a}$ & $167 \sim 290$ & $29.33 \mathrm{bf}$ & $81.0 \mathrm{acg}$ \\
\hline S $-121 \times$ ТP -509 & $105 \mathrm{abc}$ & $37 \sim 173$ & $203 \mathrm{a}$ & $139 \sim 297$ & $47.33 \mathrm{ae}$ & $67.0 \mathrm{bd}$ \\
\hline S $-121 \times$ TP -510 & $37 \mathrm{~d}$ & $23 \sim 58$ & $233 \mathrm{a}$ & $192 \sim 306$ & $15.67 \mathrm{c}$ & 83.0 af \\
\hline S-121 $\times$ TP-511 & $36 \mathrm{~d}$ & $22 \sim 48$ & $209 a$ & $176 \sim 255$ & $17.83 \mathrm{cdf}$ & 83.0 af \\
\hline S-121 $\times$ TP-512 & $114 \mathrm{a}$ & 59 167 & $231 \mathrm{a}$ & $149 \sim 298$ & $49.0 \mathrm{e}$ & $77.0 \mathrm{~g}$ \\
\hline S $-121 \times$ TP -515 & $90 \mathrm{ab}$ & $60 \sim 112$ & $217 \mathrm{a}$ & $190 \sim 266$ & 41.17 abe & $65.0 \mathrm{~d}$ \\
\hline$S-121 \times I-506$ & $122 \mathrm{a}$ & $69 \sim 180$ & $252 \mathrm{a}$ & $179 \sim 352$ & 35.85 ae & $92.0 \mathrm{e}$ \\
\hline
\end{tabular}

per capitulum, which ranges from 203 to 252 . This could be because all the combinations use the same female parent and the number of seeds in the capitulums was relatively stable.

The seed setting rates vary from $15.67 \%$ to $49.0 \%$. The cross S-121 × TP-512 shows the highest seed setting rate of $49.0 \%$, and it had significant difference with S-121 $\times$ TP508, S-121 $\times$ TP-510 and S-121 $\times$ TP-511. This is closely followed by the cross S-121 $\times$ TP-509 (47.33\%), S-121 $\times$ TP-515 (41.17\%) and S-121 $\times$ TP-379 (37.83\%), which is higher than that of the intraspecific cross S-121 $\times$ I-506 (35.85\%).

For the $F_{1}$ crosses, the seed germination rate has an important effect on the application and marketing of new varieties. The germination rates of all the crosses varied greatly. The intraspecific combination S-121 $\times$ I-506 showed the highest germination rate of $92.0 \%$. While, the germination rate of the interspecific hybrids were lower in general, ranging between $65.0 \%$ and $84.0 \%$.

The compatibility of the interspecific hybridization between $T$. erecta and T. patula depends on the genotype of the parents (Li et al., 2005; He et al., 2016). The cross S-121 $\times$ TP-379, shows the highest germination rate at $84 \%$ and had medium seed setting rate. The cross S-121 $\times$ TP-512 displays relatively low germination rate of $77.0 \%$, while it has the highest seed setting rate. Therefore, the hybrid combination with both high seed setting rate and germination rate could be obtained by parent selection.

The seed setting rate is an important indicator of the seed yield of new varieties. As shown in a previous study ( $\mathrm{He}$ et al., 2016), seven out of 15 combinations of crosses between tetraploid T. erecta and T. patula lines produced hybrid seeds, and the highest seed setting rate was $24.12 \%$. In our research, the cross S-121 $\times$ TP-512 showed the highest seed setting rate of $49.0 \%$. The two values are almost double the difference, and this may be due to differences in parental genotype and the environment under which pollination occurs.

This study shows that most of the interspecific crosses had a higher seed setting rate than the inner-specific ones. In many cases, the distant species often have different degrees of spatial and temporal isolation, different genetic material and information and inconsistent physiology, and they may cause difficulty in successfully hybridizing due to reproductive barriers (Deng et al., 2012). Reproductive barrier always exist in distant hybridization and render it unsuccessful (Deng et al., 2010). Better hybridization affinity can be achieved when the parents have a close genetic distance ( $\mathrm{Li}$ et al., 2008). The two marigolds are two species and had reproductive isolation. However, they can produce seeds when crossed by artificial pollination; this indicates that the two species have a relatively close genetic relationship. Previous research suggested that $T$. patula was a close sibling species of $T$. erecta and $T$. patula might be an amphidiploid from T. erecta and T. tenuifolia or a species closely related to them (Towner, 1961). Some studies also proved this hypothesis (Zeng et al., 2010; He et al., 2016).

Additional research about homologous chromosome pairing is suggested to conduct and observe if the synaptonemal complex could form.

The traits and heterosis of offspring resulting from crossbreeding

In whole plant type, the $F_{1}$ plants of these seven combinations show no main stem, similar to their male parent varieties.

Fig. 1 shows the quantitative characteristics of the combinations and their parents. For the plant height, seven combinations are shorter than their female parents, but taller than their male parents (Fig. 1a). For plant width, the $F_{1}$ hybrids are better than their male parents (Fig. 1b). For the flower size, all the combinations are larger than their male parents (Fig. 1c). For the trait of number of ray florets, 
680

all the $F_{1}$ offspring show more ray florets than their male parents (Fig. 1d). In addition, for the trait of days leading to flowering, the combinations bloom earlier than their male parents with the exception S-121 × TP-510 and S-121 $\times$ TP-511, which bloom 5 and 4 days later than their male parents, respectively (Fig. 1e).

For the quality characters, the traits of flower color, almost all of the combinations exhibit the same color with their male parents, except the cross S-121 × TP-512, whose flower color is orange (17A) and red $(24 \mathrm{~A})$, with a gradual conversation from red color to orange along with blossom (Fig. 2).
As shown in Fig. 2, the female parent has no petals and pollen, and the male parents show different flower types including the anemone form (TP-379, TP-508, TP-509 and TP-512), crested (TP-510 and TP-511) and semidouble (TP-515). For the $\mathrm{F}_{1}$ hybrids, the flower patterns of the crosses S-121 × TP-510 and S-121 × TP511 are the same as that of their male parents. The crosses $S$ $121 \times$ TP-508, S-121 × TP-509, S-121 × TP-512, S-121 TP-515 and S-121 $\times$ TP-379 display fully double flowers which differ from their male parents.

The ploidy level of each progeny material was estimated using flow cytometry analysis and chromosome counting.
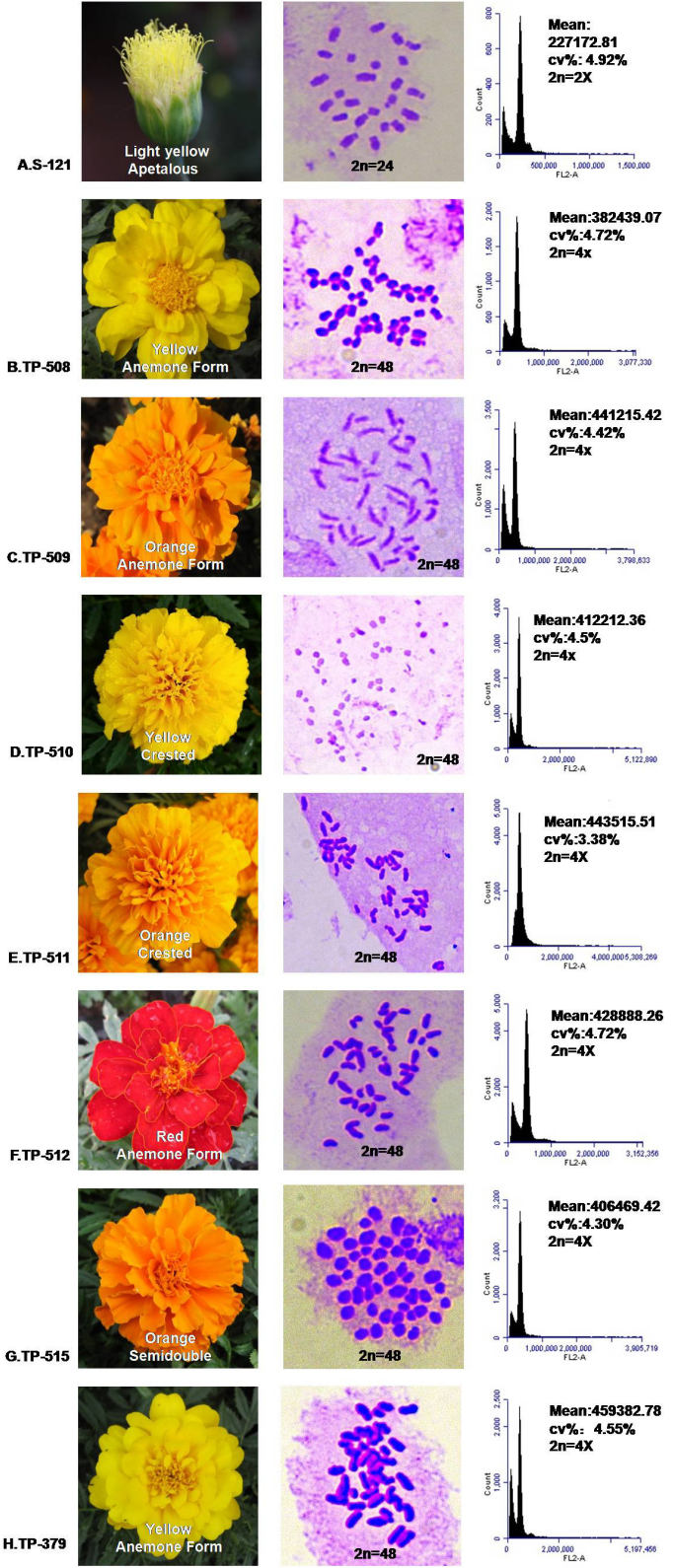
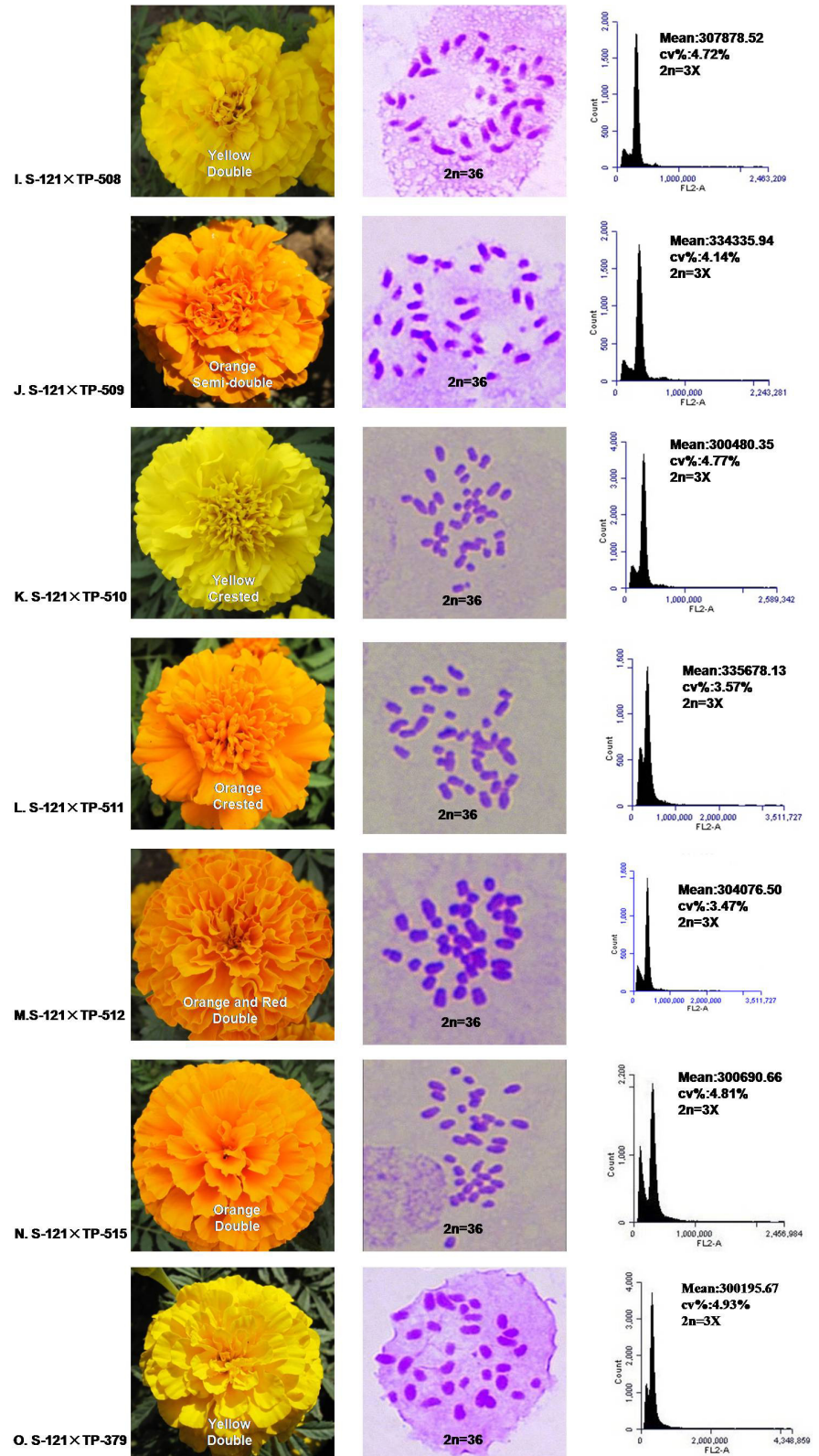

Fig. 2. The flower traits, chromosome counting and flow cytometry analysis for the parent lines of T. erecta and T. patula and their $\mathrm{F}_{1}$ hybrids 
According to Fig. 2, the S-121 of T. erecta was diploid; all of the male parents of $T$. patula were tetraploids, and the combinations were triploids.

T. erecta is naturally diploid $(2 n=2 x=24)$ while $T$. patula is allotetraploid $(2 n=4 x=48)$ (Towner 1961; Chen et al., 1982; Qi et al., 2008; He et al., 2016).Thus, the chromosome number of the interspecific combinations of T. erecta and T. patula is $2 n=3 x=36$ (Chen et al., 1982). Our results are consistent with the previous research.

The heterosis over male-parent for the five quantitative traits including plant height, plant width, flower size, number of ray florets and days leading to flowering were examined. The details are listed in Table 4. Most combinations had heterosis advantage compared with the male parent, with the exception of days leading to flowering. For plant height, the heterosis ranges from $13.6 \%$ to $60.4 \%$, and the hybrid combination S-121 $\times$ TP-509 recorded the highest percentage of heterosis. The heterosis of the plant spread has a range of $2.9 \% \sim 51.6 \%$, and the cross $S-121 \times$ TP-379 obtained the highest heterosis of $51.6 \%$, closely followed by the cross of S-121 × TP-509 (31.5\%). The heterosis of flower size varied from $5.2 \%$ to $27.1 \%$, and the heterosis of S-121 × TP-510 displayed the highest value. The highest heterosis for the ray floret number was attained by the cross S-121 $\times$ TP-379 (306.0\%), which was closely followed by the cross of S-121 × TP-509 (198.2\%). Most crosses have negative heterosis over their male parents for days leading to flowering with two exceptions.

\section{Field performance of the best crosses}

According to the main ornamental traits, including the flower pattern and color, flower number of individual plant and uniform population, both S-121 $\times$ TP-379 and S-121 $\times$ TP-512, are the best combinations. The performances are shown in Fig. 3. The two combinations show double flowers, compact plants and early flowering, which meet breeding target and market demands. S-121 $\times$ TP-379 have a relatively high seed setting rate $(37.83 \%)$ and the highest germination rate of $84.0 \%$, and with a mean of $26.2 \mathrm{~cm}$ in height, and $33.2 \mathrm{~cm}$ in plant width, double gold flower which is $6.3 \mathrm{~cm}$ in diameter and 54 days from sowing to flowering (Fig. 1, Fig. 3A, 3B).

S-121 $\times$ TP-512 have the highest seed setting rate of $49.0 \%$ and germination rate of $77.0 \%$, with a height of 25 $\mathrm{cm}$, spread of $36.4 \mathrm{~cm}$, red and orange double flower, which is $6.7 \mathrm{~cm}$ in diameter, and 53 days from sowing to flowering (Fig. 1, Fig. 3C, 3D).

Table 4. Heterosis over the male-parent for the 5 ornamental traits in different crosses of T. erecta and T. patula

\begin{tabular}{|c|c|c|c|c|c|}
\hline Cross & $\begin{array}{l}\text { Plant height } \\
(\%)\end{array}$ & $\begin{array}{c}\text { Plant spread } \\
(\%)\end{array}$ & $\begin{array}{c}\text { Flower size } \\
(\%)\end{array}$ & $\begin{array}{c}\text { Number of ray } \\
\text { florets (\%) }\end{array}$ & $\begin{array}{c}\text { Days leading to } \\
\text { flowering (\%) }\end{array}$ \\
\hline S-121 × TP-508 & $42.5 \mathrm{ad}$ & $2.9 \mathrm{ac}$ & $9.8 \mathrm{ad}$ & $148.9 \mathrm{a}$ & $-14.5 \mathrm{a}$ \\
\hline S-121 × TP-509 & $60.4 b$ & $31.5 \mathrm{~b}$ & $5.4 \mathrm{a}$ & $198.2 \mathrm{a}$ & $-11.7 \mathrm{a}$ \\
\hline S-121 × TP-510 & $42.5 \mathrm{abf}$ & $7.4 \mathrm{c}$ & $27.1 \mathrm{~b}$ & $36.1 \mathrm{~b}$ & $9.8 \mathrm{~b}$ \\
\hline S-121 $\times$ TP -511 & $41.9 \mathrm{df}$ & $14.4 \mathrm{abc}$ & $5.2 \mathrm{ac}$ & $45.6 \mathrm{~b}$ & $7.8 \mathrm{~b}$ \\
\hline S-121 $\times$ TP -512 & $13.6 \mathrm{cg}$ & $12.7 \mathrm{abc}$ & $13.6 \mathrm{~d}$ & $170.4 \mathrm{a}$ & $-5.4 c$ \\
\hline S-121 $\times$ TP -515 & $25.1 \mathrm{cde}$ & $15.6 a b c$ & $6.6 \mathrm{ac}$ & $143.6 \mathrm{a}$ & $-3.7 \mathrm{~cd}$ \\
\hline S-121 × TP-379 & $37.2 \mathrm{aef}$ & $51.6 \mathrm{~d}$ & $6.8 \mathrm{ac}$ & $306.0 \mathrm{c}$ & $-1.8 \mathrm{~d}$ \\
\hline
\end{tabular}

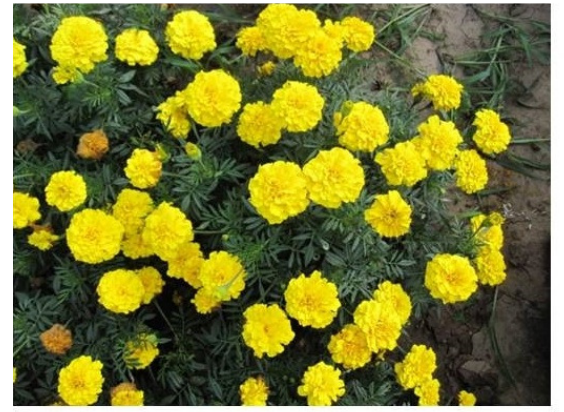

A. Individual plant of S-121 $\times$ TP-379

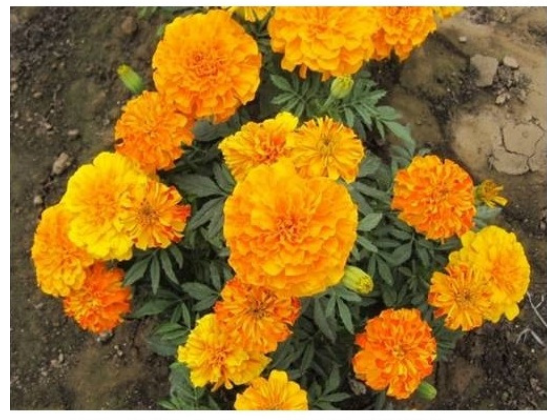

C. Individual plant of S-121 $\times$ TP-512

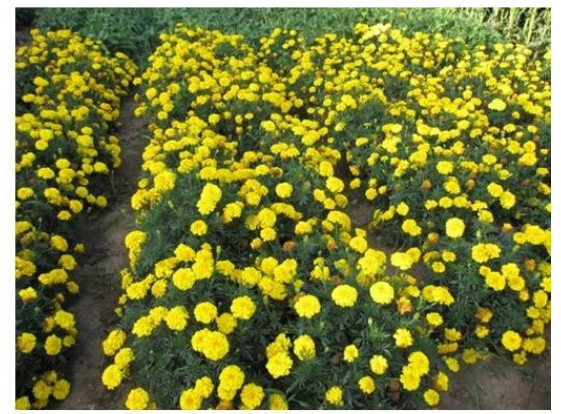

B. Population performance of S-121 $\times$ TP-379

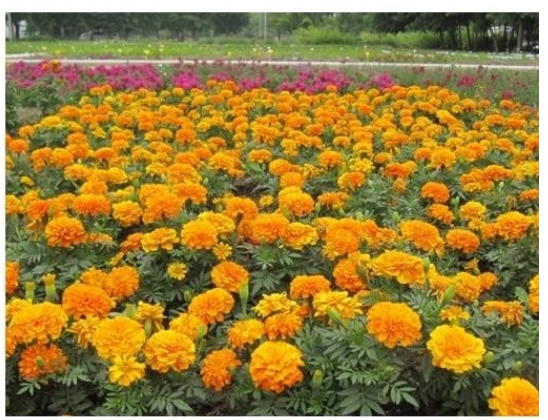

D. Population performance of S-121 $\times$ TP-512

Fig. 3. Individual and population performance of the selected combinations 
682

\section{Conclusions}

Hybridization between the male sterile line of the African marigold and inbred lines of French marigold was a good way to create better ornamental traits of marigold. According to the primary traits of compatibility, heterosis over male parents, and field performance, the crosses of $S$ $121 \times$ TP-379 and S-121 $\times$ TP-512 meet the breeding demand and were selected as the best combinations. S-121 $\times \mathrm{TP}-515$ has a relatively low germination rate, and further research is required to determine the reason. In addition, more studies about multiyear and multisite trials of variety performances and seed production should be conducted for the future promotion of the selected crosses.

\section{Acknowledgements}

This work was supported by the National Natural Science Foundation of China (grant number 31572166).

\section{References}

AiY,He YH, Hu Y,Zhang Q, Pan C, Bao MZ (2014). Characterization of a novel male sterile mutant of Tagetes patula induced by heat shock. Euphytica 200(2):159-173.

Ai Y, Zhang CL, Sun YL, Wang WN,He YH,Bao MZ (2017). Characterization and functional analysis of five MADS-box B class genes related to floral organ identification in Tagetes erecta. PLoS One 12(1):e0169777.

Ai Y, Zhang QH, Pan C, Zhang HY, Ma S, He YH, Bao MZ (2015). A study of heterosis, combining ability and heritability between two male sterile lines and ten inbred lines of Tagetes patula. Euphytica 203(2):349366.

Baciu A, Pamfil D, Sestras A, Mihalte L, Sestras R (2012). Heterosis studies for response to Aphisfabae attack in Calendula. Bulletin of University of Agricultural Sciences and Veterinary Medicine Cluj-Napoca. Horticulture 69(1):40-47.

Chen JF, Lin YJ (1982). Chromosome pairing in interspecific hybrids of Tagetespatula and Tagetes erecta marigold. Cytologia 47(3-4):737-742.

Cicevan R, Al Hassan M, Sestras AF, Prohens J, Vicente O, Sestras RE, Boscaiu M (2016). Screening for drought tolerance in cultivars of the ornamental genus Tagetes (Asteraceae). PeerJ 4:e2133.

Deng YM, TengNJ, Chen SM, Chen FD, Guan ZY, Song AP, Chang QS (2010). Reproductive barriers in the intergeneric hybridization between Chrysanthemum grandiflorum (Ramat) Kitam and Ajania przewalskir Poljak. (Asteraceae). Euphytica 174(1):41-50.
Deng YM, Ye XQ (2012). The prefertilization reproductive barriers and overcoming methods of horticultural crops distant hybridization. Acta Agriculturae Boreali-Sinica 27(S1):81-86.

He YH, Ning GG, Sun YL, Qi YC, Bao MZ (2009). Identification of a SCAR marker linked to a recessive male sterile gene (Tems) and its application in breeding of marigold (Tagetes erecta). Plant Breeding 128(1):92-96.

He YH, Sun YL, Zheng RR, Ai Y, Cao Z, Bao MZ (2016). Induction of tetraploid male sterile Tagetes erecta by colchicine treatment and its application for interspecific hybridization. Horticultural Plant Journal 2(5):284-292.

Li FR, ZhangJC, Xu JR, Zhou JH (2005). Studies on the cross-breeding of Tagetes erecta L. $\times$ Tagetes patula L. and the sterility of hybrid. Inner Mongolia Agricultural University 26(2):51-54.

Li XI, Chen FD, Zhao HB (2008). Compatibility of interspecific cross in Dendranthema genus. Acta Horticulturae Sinica 35(2):257-262.

Namita N, Singh KP, Bharadwaj C, Sharma TR, Sonah H, Raju DVS, Deshmukh RK (2011). Gene action and combining ability analysis for flower yield and its component traits in interspecific hybrids of marigold (Tagetes spp). Indian Journal of Agricultural Sciences 81(9):807-811.

Namita N, Singh KP, Bharadwaj CP, Prasad KV, Raju DVS (2009). Studies on character association and path analysis of quantitative traits among parental lines of marigold (Tagetes erecta and T. patula) and their interspecific $F_{1}$ hybrids. Indian Journal of Horticulture 66(3):348-352.

Qi YC,Zhou GL, Gao Y (2008). Study on squash technique of root tip and analysis of chromosome karyotype in Tagetes patula. Journal of Hubei University for Nationalities (Natural Science Edition) 26(3):261-265.

Sreekala C, Raghava SPS (2003). Exploitation of heterosis for carotenoid content in African marigold (Tagetes erecta L.) and its correlation with esterase polymorphism. Theoretical Applied Genetics 106(4):771-776.

Towner JW (1961). Cytogenetic studies on the origin of Tagetes patula. I. meiosis and morphology of diploid and allotetraploid T. erecta $\times T$. tenuifolia. American Journal ofBotany 48(9):743-751.

Wu RH, Ge BB, Wang ML, Zhou Y, Feng H (2016). Estimation of genome size of eighteen Chinese old garden roses by flow cytometry. Journal of BeijingForestry University 38(6):94100.

Zeng L, Zhao LJ, Sun J, Zhao ZG, Yang F (2010). Analysis of genetic relatedness of genetic resources of Tagetes as revealed by ISSR Scientia AgriculturaSinica43(1):215-222.

Zhang HL, Dong AX, Wang T, Zhao LJ, Xin HB (2014). A New Cultivar of Marigold 'Jingyue 1'. ActaHorticulturae Sinica 41(7):1521-1522.

Zhu C (1982). Plant chromosome and chromosome technology. Beijing. Science Press. 